\title{
Communications
}

\section{Société Suisse de Neurophysiologie Clinique}

Examen pour l'obtention des certificats Electroencéphalographie (SSNC), Electroneuromyographie (SSNC), Maladies Cérébrovasculaires (SSNC)

Pour l'obtention des certificats Electroencéphalographie (SSNC), Electroneuromyographie (SSNC) et Maladies Cérébrovasculaires (SSNC) il est nécessaire de réussir un examen final théorique et pratique en complément des autres conditions requises. Ces dernières sont disponibles sur le site internet: www.fmh.ch. Les collègues qui s'annoncent pour l'examen sont prié(e)s de déposer leur dossier jusqu'au 15 octobre 2014 avec les documents suivants. Les formulaires d'inscription peuvent être téléchargés à partir du www.sgkn.ch sous la rubrique examens.

Date:

jeudi et vendredi, le 27 et 28 novembre 2014
Lieu: Hôpital cantonal de St-Gall, Service de Neurologie

Frais d'inscription: pour les membres de la SSNC $700 \mathrm{CHF}$, pour les non membres $1200 \mathrm{CHF}$

L'inscription: Secrétariat de la SSNC/SGKN, Mme Christa Kubat, Blumenweg 13, 5036 Oberentfelden, tél. 06272342 80, Fax 0627234281. sgkn[at]bluewin.ch, www.sgkn.ch

Date limite: 15 octobre 2014

\section{Sujets actuels de forum}

Joignez la discussion en ligne sur www.saez.ch

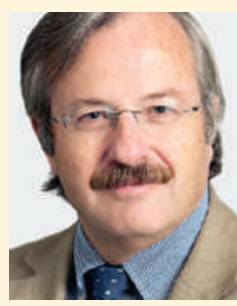

Prof. Dr méd. Dr h. c. Max Aebi, Senior Consultant de l'Institut de recherche évaluative en médecine (IEFM) de l'Université de Berne et Président de la Fondation SIRIS

\section{Contrôle de qualité en chirurgie}

Qu'apportent les registres?

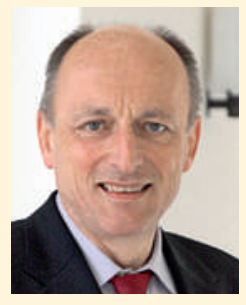

Prof. Dr méd. Peter Meier-Abt, membre du Conseil d'experts du Swiss Medical Board (SMB)

\section{Débat sur la mammographie: prise de position du SMB}

Diverses publications concordent avec les recommandations du SMB

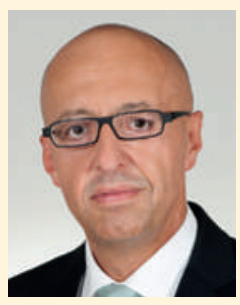

Andreas Faller, gérant de l'entente système de santé libéral

\section{Négociations TARMED}

Ensemble contre les interventions de l'Etat 